\title{
RELEVÂNCIA DA PRODUÇÃO TÉCNICO-CIENTÍFICA NO CONTEXTO DO MESTRADO PROFISSIONAL EM DESIGN DA UNIVILLE
}

\author{
Marli Teresinha Everling \\ Univille \\ marli.everling@gmail.com \\ João Eduardo Chaga Sobral \\ Univille \\ sobral41@gmail.com \\ Anna Luiza Moraes de Sá Cavalcanti \\ Univille \\ anna.cavalcanti08@gmail.com
}

\author{
Victor Rafael Laurenciano Aguiar \\ Univille \\ contato@ograndevendedor.com.br \\ Adriane Shibata Santos \\ Univille \\ adriane.shibata@univille.br \\ Elenir Carmen Morgenstern \\ Univille \\ elenir.m@gmail.co
}

Resumo: o Programa de Pós-Graduação em Design da Universidade da Região de Joinville (PPGDesign/Univille) situa-se na modalidade de mestrado profissional. Este artigo se propõe a provocar discussões acerca das características e desafios relacionados à produção técnico-científica no cenário educativo dos mestrados profissionais. Discute-se, pois, ao longo deste, a relevância da produção técnicocientífica e desafios relacionados à sua configuração e viabilização. Para isso foram consultados documentos próprios do PPGDesign/Univille e diretrizes disponibilizadas pela Coordenação de Aperfeiçoamento de Pessoal de Nível Superior (CAPES). Espera-se identificar desafios e oportunidades e compartilhá-los com a comunidade acadêmica, contribuindo com o amadurecimento dos mestrados inseridos nesta modalidade.

Palavras-chave: Design, Mestrado Profissional, Produção Técnico Científica

\begin{abstract}
:
The Post Graduate Program in Design at the University of Joinville Region (PPGDesign/Univille) is situated in the Professional Master mode. This paper aims to discuss the Features and the Challenges related to scientific and technical output in the educational scenario of Professional Masters. Therefore, this canvass relies on the relevance of scientific and technical production and on the challenges related to its configuration and feasibility. Hence were consulted specific documents of the PPGDesign/Univille and available guidelines authored by "Coordenação de aperfeiçoamento de Pesssoal de Nivel Superior" (CAPES). It is expected identify challenges, opportunities and share them with the academic community, contributing with the ripeness of the masters courses featured like professional.
\end{abstract}

Keywords: Design, Professional Master Courses, scientific and technical output 


\section{INTRODUÇÃO}

Os mestrados profissionais no Brasil apresentam-se como uma nova modalidade de Strictu Senso, diferente dos programas acadêmicos, consolidados há mais de meio século. Buscam valorizar o conhecimento técnico-científico aplicado e, assim, fortalecer os laços com o setor produtivo. É neste cenário que foi criado o Mestrado Profissional em Design da Universidade da Região de Joinville (Univille), que nos últimos quatro anos tem contribuído com a pesquisa técnico-científica por meio da realização de trabalhos de conclusão de curso (TCC), bem como com projetos de ensino, pesquisa e extensão. Ao longo de sua curta existência está fortalecendo parcerias com os mais diversos setores produtivos catarinenses. Partindo da consolidação necessária dos novos programas de pós-graduação, no contexto do design, este artigo propõe como objetivo a contextualização da natureza do PPGDesign/Univille em uma discussão sobre a relevância da produção técnicocientífica, em seus diversos formatos. Como fundamentos para esta reflexão foram consultadas, a proposta de criação do PPGDesign/Univille e os relatórios anuais das atividades do programa preparados e encaminhados para a CAPES por meio da plataforma sucupira. Destaca-se que a redação coletiva deste ensaio se constitui também em oportunidade para reflexão sobre a prática, contribuindo para sua constante revisão.

Entretanto, a principal intenção é identificar desafios e oportunidades e compartilhá-los com a comunidade acadêmica da área do design no âmbito da pósgraduação, no intuito de contribuir com o encaminhamento e o amadurecimento de ações associadas à produção técnico-científica, que é preponderante sobre a produção científica quando se trata dos mestrados profissionais.

\section{CONTEXTUALIZAÇÃO DOS MESTRADOS PROFISSIONAIS E DO PPGDESIGN DA UNIVILLE}

Discorrer acerca da produção técnico-científica dos Mestrados Profissionais em Design no Brasil carece de uma revisão dos documentos e legislações que amparam e orientam tal produção. Os Mestrados Profissionais, de acordo com o Documento de Área 2013, integram a Área de 'Arquitetura, Urbanismo e Design' que, por sua vez, está interligada à grande área 'Ciências Sociais Aplicadas'.

A área 'Arquitetura, Urbanismo e Design' envolve, de acordo com o mencionado documento, campos do conhecimento que transitam no âmbito da arte, ciência e tecnologia. Essa amplitude, segundo o mesmo documento, permite múltiplas possibilidades de inserção, entre teoria e prática, com destaque para projeto, planejamento, gestão, inovação, relacionadas ao ambiente construído e natural, objetos, produtos, serviços, como contribuição para o bem-estar da população e para a satisfação de suas necessidades materiais, sociais, culturais.

Suas duas subáreas, 'arquitetura e urbanismo' e 'design', conforme destaca o documento, possuem interfaces e especificidades que, pela amplitude de atuação e abordagem, exigem uma interação entre elas e um permanente diálogo com outras áreas do conhecimento, o que confere à Área de Arquitetura, Urbanismo e Design, a condição de interdisciplinar. Assim, a criação, a preservação e o desenvolvimento de artefatos, tecnologias, sistemas, serviços e ações sobre objetos, espaço e ambiente, são de grande importância para a área. 
Em maio de 2012, quando o PPGDesign/Univille estava em fase de concepção, foi realizado o seminário internacional A Metropolização Brasileira e os Desafios da Gestão Urbana: O Papel da Pós-graduação, promovido pela CAPES. Neste evento o presidente da organização, Jorge Almeida Guimarães, demonstrou sua expectativa de que o seminário apresentasse importantes conclusões para a política de indução da CAPES, resultando na formação de recursos humanos qualificados. Entre os princípios abordados ao longo do seminário, destacam-se como relevantes para a construção desta proposta: (1) priorização da interdisciplinaridade; (2) transversalidade entre os temas e (3) a consideração das dimensões materiais, sociais e ambientais da vida urbana e suas múltiplas relações.

Tal orientação da CAPES, paralelamente ao cenário industrial de Joinville, contribuiu para que a proposta do PPGDesign/Univille se situasse como mestrado profissional e considerasse o design não apenas pelo viés do produto, como também dos serviços, criando espaço para a capacitação de profissionais na área do design voltados à solução de problemas complexos e inseridos em uma abordagem sistêmica considerando desafios associados aos setores produtivo, público e social.

\subsection{O mestrado profissional da Univille}

Joinville é uma cidade localizada a nordeste de Santa Catarina, com aproximadamente 560 mil habitantes (IBGE, 2014) e com um produto interno bruto correspondente a aproximadamente $\mathrm{R} \$ 18,3$ milhões (JOINVILLE EM DADOS, 2015).

A cidade possui o maior parque exportador de Santa Catarina, sendo responsável por $20 \%$ das exportações catarinenses, e caracteriza-se por uma indústria atuante nas áreas de metal-mecânica, plásticos, têxtil, madeireira, química, farmacêutica, tecnologia da informação, entre outras, constituindo-se no terceiro polo industrial da Região Sul.

A Univille é uma universidade comunitária, cujas especificidades são: ter sido criada e mantida pela sociedade e sua contribuição com o desenvolvimento local e regional. Tem como características: respostas às demandas da sociedade, sinergia com a comunidade regional, além da oferta de acesso ao ensino superior à população em geral.

O comprometimento da Univille com o desenvolvimento regional também é perceptível por sua participação em organizações como Associação Comercial e Industrial de Joinville (ACIJ), Associação de Joinville e Região da Pequena, Micro e Média Empresa (AJORPEME), Serviço Brasileiro de Apoio às Micro e Pequenas Empresas (SEBRAE) e pela coautoria em incubadoras como a Fundação Softville e o Parque de Inovação Tecnológica de Joinville e Região (INOVAPARQ).

O curso de Graduação em Design da Univille foi o pioneiro na formação de designers em Santa Catarina. Em 2008, diante do visível crescimento de oportunidade na área, foi aprovado pelos conselhos superiores da instituição a criação de um curso de Mestrado em Design para o biênio 2012-2013.

A configuração da proposta do mestrado fundamentou-se: (1) no cenário e nas discussões da administração pública, do setor industrial de Joinville e região; (2) na posição econômica e geográfica de Joinville; (3) no número de profissionais formados em Design pela Univille e por outras instituições situadas na região; (4) no número de instituições de ensino superior que oferecem cursos como Engenharia, Gestão/Administração e Design, profissionais que podem se beneficiar com a 
capacitação que se pretende oferecer por meio do Mestrado Profissional em Design; e (5) no crescimento de $425,5 \%$ (entre 2002 e 2012) de profissionais buscando qualificação por meio de programas de mestrado e doutorado.

Já a decisão de situar Design e Sustentabilidade como Área de Concentração do Mestrado Profissional (Figura 1) foi apoiada na expertise técnico-científica de seus professores e na intenção de preencher uma lacuna existente na capacitação profissional em nível de mestrado na região norte de Santa Catarina, caracterizada pelo diversificado e forte parque fabril.

A Proposta do PPGDesign/Univille considera o design de produtos e serviços, criando espaço para a capacitação de profissionais na área do design voltados à solução de problemas complexos e inseridos em uma abordagem sistêmica. 0 programa dedica permanente atenção à análise e à renovação do conceito de projeto e seus desenvolvimentos, com vistas à inovação e à inserção de novas tecnologias, fortalecendo, constantemente, o espírito empreendedor, tão consagrado na região de Joinville.

O Curso de Mestrado Profissional em Design da Univille contribui para a qualificação de profissionais comprometidos com a produção de conhecimento técnico-científico dirigida para a solução de problemas relacionados ao design de produtos e serviços sob o foco da sustentabilidade no contexto urbano, industrial e artesanal. Deste modo, observa-se o potencial do PPGDesign para capacitação de recursos humanos para a indústria, o setor público e o educacional. O quadro 1 apresenta a Área de Concentração e Linhas de Atuação do PPGDesign /Univille:

Quadro 1 - Configuração do PPGDesign/Univille

\section{Área de Concentração}

Design e Sustentabilidade: compreende questões e aspectos relacionados ao design no contexto urbano e em empresas de diversos segmentos industriais ou artesanais, com abrangências analítica, metodológica, de pesquisa aplicada e teórico-reflexiva. Considera as transformações sociais, culturais e tecnológicas, discutindo o papel dos profissionais que atuam nesse contexto.

Linhas de Atuação [LA]

\section{[LA1] Produção do Design e Contexto}

Sociocultural: investiga as relações do design com a realidade social, considerando o contexto urbano, o mercado, o comportamento do consumidor, a sociedade, a cultura material e suas questões simbólicas e estéticas. Abrange a influência e as ações do design na reprodução dos valores culturais e sociais, objetivando o desenvolvimento de produtos e serviços sustentáveis.
[LA2] A linha de atuação em Produção Tecnológica e Sustentabilidade: investiga questões direcionadas ao estudo das relações usuário-objeto e meio ambiente, levando em conta aspectos de interface, interações físicas e sustentabilidade. Abrange novas possibilidades em relação aos aspectos de desenvolvimento, produção e gestão do processo de design e do desenvolvimento de produtos e serviços.

Fonte: Elaborado pelos autores a partir da APCN do curso (UNIVILLE) 
A estruturação das atividades técnico-científicas (pesquisa, extensão e sua articulação com o ensino e a transferência de conhecimento para os setores produtivo, público, social) ocorrem por meio dos grupos de pesquisa IRIS, LECid, Design/Cultura/Sociedade e Design de Serviços, certificados pelo CNPq, conforme destacado no Quadro 2:

\section{Quadro 2 - Grupos de Pesquisa do PPGDesign/Univille}

Laboratório IRIS, que tem como foco o estudo da representação e a linguagem visual, registrado no diretório de grupos de pesquisa CNPq. Conta com alunas de graduação, com projetos de iniciação científica, alunos de mestrado e professores. 0 grupo desenvolve-se com orientações e um grupo de leitura com encontros semanais. Como resultado o grupo aprovou um projeto no edital universal que permitiu o início da consolidação do laboratório de materiais;

Grupo de Pesquisa em Design, Cultura e Sociedade, investiga as relações do design com a realidade social, considerando o contexto urbano, mercadológico e a sociedade; as ações do grupo de pesquisa incluem projetos de extensão universitária, denominados SempreViva e AmaViva, que apoiam de maneira prática, por meio da pesquisa aplicada, as investigações teóricas. O grupo conta com professores, alunos do mestrado e de iniciação científica e de extensão.

\section{Grupo de Pesquisa LECid (Laboratório de} Estudos em Design-Cidade), possui no espaço urbano considerando design, sustentabilidade, mobilidade e relações de uso. O grupo conta com a participação de professores, alunos de mestrado, de iniciação científica e de alunos de TCC. Como resultado o grupo integra a rede que reúne organizações civis e públicas orientadas para a temática, promove eventos anuais e possui um grupo de estudo.

Grupo de Pesquisa em Design de serviços visa fomentar a melhoria dos processos de organizações de serviços de Joinville e região e, intermediar a relação academia e organizações, oportunizando aos mestrandos um campo de estudo e prática. Dentre os estudos destaca-se a realização de consultorias e workshops com foco na temática.

Fonte: Elaborado pelos autores a partir do CNPq

Considerando as características do curso acima apresentadas e a natureza de um mestrado profissional, nota-se a relevância da produção técnico-científica e suas especificidades; neste sentido, na sequência, discute-se como este desafio tem sido afrontado e que possibilidades o PPGDesign/Univille tem vislumbrado ao longo de sua trajetória.

\subsubsection{A produção técnica no mestrado profissional}

Entre os tópicos do Plano Nacional de Pós-Graduação (PNPG) 2011-2020, está a discussão a respeito do papel da pós-graduação para a capacitação de recursos humanos para as empresas como estratégia para a inovação. De acordo com o documento, esforços significativos vêm sendo feitos entre a Coordenação de Aperfeiçoamento de Pessoal de Nível Superior, (CAPES), o Conselho Nacional de Desenvolvimento Cientifico e Tecnológico (CNPq) e a Financiadora de Estudos e Projetos (FINEP), no intuito de orientar a pós-graduação como tática para desenvolvimento sócio econômico nacional. Como diagnóstico para o vínculo frágil entre as Instituições de Ciência e Tecnologia (ICTs) e empresa, o documento aponta três causas: (1) a escassez da cultura de inovação nas empresas, (2) as ICTs ainda focadas no processo tradicional de produção de conhecimento e na formação de 
recursos humanos; e (3) as instituições acadêmicas atuarem no longo prazo enquanto o setor produtivo opera com cronogramas de urgência.

Este tópico é encerrado com a apresentação de vários desafios associados à ciência, tecnologia, inovação e, mais especificamente, entre academia e setor produtivo. O quadro 3 apresenta as informações extraídas deste documento, que estruturam parte da conduta adotada no PPGDesign/Univille:

\section{Quadro 3 - Desafios para integração entre academia \& setor produtivo}

Estratégias para qualificação do ensino em todos os níveis, ampliando e diversificando o ensino médio e a educação superior.

Formas de inserção de jovens de nível técnico no mercado de trabalho assim como de quadros formados por instituições de educação superior.

Absorção de mestres e doutores por empresas;

Ênfase em áreas tecnológicas e engenharias na pós-graduação brasileira visando a contribuição estratégica para o desenvolvimento de setores como energia, telecomunicações, automotivo, saúde, eletrodomésticos, agronegócio, alimentos e têxtil.

Formação de talentos na pós-graduação no intuito de cooperar com os processos de inovação do setor produtivo, considerando cenários futuros, tendências futuras, robustecendo habilidades e competências adequadas a competitividade global;

Integração de universidades, governo e empresas constituindo redes de produção de conhecimento, fundamentadas nas interdisciplinaridade, aplicabilidade e responsabilidade social do conhecimento, (com políticas indutoras para a pesquisa com foco em tecnologias sociais e com ênfase na sustentabilidade)

Fonte: Elaborado pelos autores a partir do Plano Nacional De Pós-Graduação (PNPG) 2011-2020

O quadro 4, a seguir, destaca como a conduta do PPGDesign/Univille tem se orientado neste sentido.

\section{Quadro 4 - Resposta aos desafios para integração entre academia \& setor produtivo no PPGDesign/Univille}

\section{ESTRATÉGIAS PARA QUALIFICAÇÃO DO ENSINO EM TODOS OS NÍVEIS, AMPLIANDO E DIVERSIFICANDO O ENSINO MÉDIO E A EDUCAÇÃO SUPERIOR:}

Considerando o ensino formal, ações neste sentido têm sido orientadas para o ensino fundamental, cursos superiores de tecnologia e bacharelados; em relação a educação informal estas estratégias se realiza por meio de projetos de extensão e trabalhos de conclusão de curso voltados para pessoas de baixa renda, terceira idade e público do terceiro setor.

\section{Ensino Fundamental}

Em 2013 foi realizado o Projeto Criar e Crescer com estudantes terceiro ano de uma escola estadual de Joinville, utilizando a metodologia Design for Change para envolver os estudantes como protagonistas do processo de qualificação do entorno da escola. Nos anos 2013/2014 foi produzido conteúdo para o Almanaque Caranguejo de Educação (distribuído em todas as escolas municipais de Joinville e com abrangência nacional) com foco em design e sustentabilidade.

\section{Cursos Superiores de Tecnologia/Bacharelados:}

\section{Educação Informal}

Três grupos direcionados para o público feminino foram beneficiados: (1) Os projetos Sempre Viva e Ama Viva desde 2013 estão associados ao PPGDesign e visam a qualificação empreendedora de mulheres de baixa renda; (2) o Instituto Consulado da mulher (que fomenta o empreendedorismo para mulheres de renda) foi foco de um trabalho de TCC que visava associar o design a produção no terceiro sector. Em relação a terceira idade 
O Curso Superior de Tecnologia em Design de Moda do Senai Curitiba foi objeto de estudo de um TCC beneficiando o corpo docente e discente do curso e abrangendo (por meio da qualificação profissional) o corpo docente. Além disso os cursos superiores de tecnologia e bacharelados também são alcançados por meio desta ação considerando que parte significativa do corpo discente do mestrado atua também na docência destes segmentos dois grupos foram contemplados: (1) 0 Grupo Pontos de amor que foi objetivo de um TCC associando conceitos como design participativo, pesquisa-ação e produção artesanal; (2) O grupo Matura Idade na Univille está vinculado ao PPGDesign desde a sua criação e visa promover a qualidade de vida e o bem-estar por meio de atividades com arte, fotografia, expressão bi-tridimensional.

FORMAS DE INSERÇÃO DE JOVENS DE NÍVEL TÉCNICO NO MERCADO DE TRABALHO ASSIM COMO DE QUADROS FORMADOS POR INSTITUIÇÕES DE EDUCAÇÃO SUPERIOR/ABSORÇÃO DE MESTRES POR EMPRESAS/CONTRIBUIÇÃO DO PPGDESIGN ESTRATÉGICA PARA O DESENVOLVIMENTO DO SETOR PRODUTIVO DA REGIÃO:

A atuação neste sentido é mais robusta por meio da qualificação de profissionais vinculados ao setor produtivo e setor educacional (considerando ensino técnico e ensino superior eempreendimentos sociais: dos 25 mestres formados pelo PPGDesign até final de 2015 , todos estão atuando no mercado de trabalho e alguns possuem duas ou até 3 ocupações. Desses, 3 são sócios proprietários de escritórios de design/arquitetura, 4 ocupam cargo de designer no departamento de design de uma indústria de eletrodomésticos,4 atuam como designers em empreendimentos sociais; 1 possui empresa de consultoria; 11 estão inseridos no mercado de trabalho como professores em instituições públicas ou privadas ou cargo administrativo em instituições de nível superior. Destaca-se ainda que a contribuição com o setor produtivo ocorre ainda por meio de projetos desenvolvidos nas disciplinas do PPGDesign (e Trabalhos de Conclusão de Curso (mais de 75\% das disciplinas e dos TCCs são articulados com o setor produtivo)

\section{HABILIDADES E COMPETÊNCIAS COM FOCO NA PRODUÇÃO TÉCNICA QUE VEM SENDO DESENVOLVIDAS POR MEIO DO PPGDESIGN:}

As habilidades e competências desenvolvidas pelo programa envolvem: sustentabilidade, design de produto/serviços, produção do conhecimento técnico-científico, cenários sociais e mercadológicos, gestão, imagem, modelagem manual e digital, relações de uso e contexto urbano.

Fonte: Elaborado pelos autores a partir de relatórios sucupira do PPGDesign/Univille para a CAPES

Considera-se que a localização de Joinville e sua vocação industrial têm contribuído para atender à orientação explícita da CAPES, no sentido de responder efetivamente aos desafios do setor produtivo, especialmente nos setores de saúde, eletrodomésticos, alimentos e têxtil. Salienta-se que entre os resultados alcançados nos Trabalhos de Conclusão de Curso (TCCs) do Mestrado em Design da Univille, incluem-se patentes e empreendimentos decorrentes.

Já a contribuição do programa com a indução da pesquisa e produção técnicocientífica orientada para tecnologias sociais (especialmente na área da sustentabilidade) está contemplada na própria área de concentração do PPGDesign/Univille e na orientação do design para a qualificação de produtos e serviços associados ao terceiro setor e a grupos sociais.

\subsubsection{A Produção científica e seus formatos: Dissertação, Relatório técnico, Memorial descritivo}

A exigência da cientificidade dos trabalhos de conclusão dos Mestrados Profissionais em Design está evidenciada na PORTARIA NORMATIVA No - 17, (de 28 de dezembro de 2009) que dispõe sobre o Mestrado Profissional no âmbito da Fundação de Coordenação de Aperfeiçoamento de Pessoal de Nível Superior - CAPES. Esta portaria destaca a necessidade de estimular a formação de mestres profissionais 
habilitados para desenvolver atividades e trabalhos técnico-científicos em temas de interesse público. Nos termos desta redação, evidencia-se a intenção de resolução de problemas públicos, que emergem nas atuais sociedades, por meio da pesquisa cuja cientificidade seja atestada.

De acordo com a mencionada portaria, em seu Artigo VII, a proposta de Mestrado Profissional deverá, necessária e obrigatoriamente, prever a defesa apropriada na etapa de conclusão do curso, possibilitando ao aluno demonstrar domínio do objeto de estudo com plena capacidade de expressar-se sobre o tema. Já o Artigo VIII destaca a exigência de apresentação de trabalho de conclusão final do curso. O inciso 3 을 do Artigo VIII, evidencia que o trabalho de conclusão final do curso poderá ser apresentado em diferentes formatos, tais como dissertação, revisão sistemática e aprofundada da literatura, artigo, patente, registros de propriedade intelectual, projetos técnicos, publicações tecnológicas; desenvolvimento de aplicativos, de materiais didáticos e instrucionais e de produtos, processos e técnicas; produção de programas de mídia, editoria, composições, concertos, relatórios finais de pesquisa, softwares, estudos de caso, relatório técnico com regras de sigilo, manual de operação técnica, protocolo experimental ou de aplicação em serviços, proposta de intervenção em procedimentos clínicos ou de serviço pertinente, projeto de aplicação ou adequação tecnológica, protótipos para desenvolvimento ou produção de instrumentos, equipamentos e kits, projetos de inovação tecnológica, produção artística, sem prejuízo de outros formatos, de acordo com a natureza da área e a finalidade do curso, desde que previamente propostos e aprovados pela CAPES. Destaca-se que o curso de mestrado do PPGDesign/Univille em sua proposta de criação do curso (2012) considera que o "projeto final de curso poderá consistir em dissertação, projeto técnico específico, estudo de caso, propriedade intelectual, patentes, depósito de patentes, projeto de produto ou serviço, trabalho científico de pesquisa em design, desenvolvimento de instrumentos, equipamentos e protótipos".

A Portaria Normativa, que delibera sobre os Mestrados Profissionais e o Documento da Área de 'Arquitetura, Urbanismo e Design', apresenta os possíveis formatos de trabalhos conclusivos de curso. No entanto, não exibem diretrizes para o desenvolvimento de tais documentos. Existe uma orientação, no Documento de Área, para que os Mestrados Profissionais indiquem em seus projetos de curso e ministrem junto aos estudantes, atividades de treinamento e caracterização do formato do trabalho de conclusão de curso, nos termos da Portaria Normativa MEC no17/2009.

Neste momento, em que os Mestrados Profissionais em Design procuram uma formatação adequada às orientações da CAPES e condizentes às expectativas sociais e aos contextos culturais nos quais se inserem, observa-se, em algumas instituições de ensino de Pós-graduação, o delinear de diretrizes que esmiúçam cada formato de trabalho. Assim, é possível acessar-se sites destas instituições, orientações apresentadas a partir da conjugação de intenções e compreensões de seus corpos docentes. Não existe um documento diretor único, para todos os Mestrados Profissionais do país, que detalhe e oriente para o desenvolvimento de cada formato de trabalho de conclusão de curso, mas sim, apresentam-se tentativas de esclarecimento que, no momento atual, são formatadas no consenso dos colegiados dos próprios Mestrados Profissionais. 


\subsubsection{Os trabalhos Realizados}

Devido ao compromisso dos mestrados profissionais em responder aos desafios dos setores produtivos, público e social, as possibilidades associadas ao projeto final de curso (dissertação, projeto técnico específico, estudo de casos, propriedade intelectual, patentes, depósito de patentes, projeto de produto ou serviço, entre outros) e a flexibilidade para que os próprios colegiados dos Mestrados Profissionais desenvolvam o formato mais apropriado, aspectos relacionados à configuração e à estruturação dos Trabalhos de Conclusão de Curso têm merecido atenção desde a concepção da proposta. Ressalta-se que apesar do constante cuidado neste sentido, é um processo ainda em construção e até o momento tem-se as seguintes diretrizes: (1) projetos caracterizados como técnicos, estudos de caso, propriedade intelectual, patentes, depósito de patentes, projeto de produto ou serviço, desenvolvimento de instrumentos, equipamentos e protótipos são entregues sob a forma de relatório técnico (o desenvolvimento privilegia o estado da técnica e o detalhamento do projeto técnico desenvolvido) ou memorial descritivo (enfatiza a descrição do desenvolvimento); (2) trabalho científico de pesquisa em design ou que possuem ênfase na discussão teórica são estruturados como dissertação (acentua a fundamentação, pesquisa e discussões teóricas); (3) estabelecimento de vínculo/ênfase da discussão com a prática profissional do mestrando e ênfase do problema de pesquisa e situações que possibilitem responder aos desafios associados ao setor produtivo/social/público.

Assim, desde o início, os trabalhos realizados pelos alunos confirmam a forte vocação do programa de preparar os estudantes, tanto para a docência quanto para a vida profissional, assim como sua forte integração com o mundo do trabalho e das organizações, uma das características do Mestrado Profissional. O quadro 5 elenca os TCCs defendidos até o início de 2016 que estão diretamente relacionados à resolução de problemas de empresas e os demais trabalhos, que mesmo não estando diretamente focados em organizações, têm uma importante contribuição social e/ou educacional.

\section{Quadro 5 - Resposta aos desafios para integração entre academia \& setor produtivo no PPGDesign/Univille}

\begin{tabular}{|l|l|}
\hline Onze trabalhos vinculados a empresas & Formato \\
\hline $\begin{array}{l}\text { Design de Embalagem de Alimento Congelado: Um Estudo de Caso da Itálica Indústria } \\
\text { e Comércio de Alimentos Ltda. }\end{array}$ & Relatório Técnico \\
\hline $\begin{array}{l}\text { A Gestão do Design como Gerador de Novas Oportunidades de Mercado na Indústria } \\
\text { Grampel. }\end{array}$ & Relatório Técnico \\
\hline $\begin{array}{l}\text { O Processo Criativo em Arquitetura e Design: Afinidades e a Discussão da Identidade } \\
\text { da Metroquadrado. }\end{array}$ & Dissertação \\
\hline $\begin{array}{l}\text { Diretrizes de Design de Interfaces para Terceira Idade: guia projetual para o } \\
\text { desenvolvimento de interfaces em refrigeradores voltados ao público idoso. }\end{array}$ & Relatório Técnico \\
\hline $\begin{array}{l}\text { Diagnóstico do Processo de Inovação no Desenvolvimento de Produtos, nas Empresas } \\
\text { do Projeto Inova Moda, em Santa Catarina. }\end{array}$ & Relatório Técnico \\
\hline Indústria de Moda e Projetos Sociais: Possíveis Práticas de Cooperação. & Dissertação \\
\hline Design e Desenvolvimento de Produtos de Moda: A organização de uma estrutura & Relatório Técnico \\
\hline
\end{tabular}




\begin{tabular}{|c|c|}
\hline $\begin{array}{l}\text { projetual para as disciplinas de Projeto de Coleção do Curso Superior de Tecnologia } \\
\text { em Design de Moda do Senai Curitiba }\end{array}$ & \\
\hline Design, Projeto e Desenvolvimento de Produto para Indústria de Mobiliário Serflex & Relatório Técnico \\
\hline Design do Equipamento NG-Tox para a Ecobabitonga Tecnologia & $\begin{array}{l}\text { Memorial } \\
\text { Descritivo }\end{array}$ \\
\hline $\begin{array}{l}\text { Design de Serviços Aplicado no Desenvolvimento de uma Plataforma Online de } \\
\text { Projetos de Interiores para Classe C }\end{array}$ & Relatório Técnico \\
\hline Aparelho para Secagem de Instrumentos Cirúrgicos & $\begin{array}{l}\text { Memorial } \\
\text { Descritivo }\end{array}$ \\
\hline Seis trabalhos vinculados a outros tipos de organizações (que não empresas) & Formato \\
\hline $\begin{array}{l}\text { Proposta de Design de Serviços para um Sistema de Design e Artesanato: uma relação } \\
\text { social recíproca. }\end{array}$ & Dissertação \\
\hline Contribuições do Design em Contexto do Terceiro Setor. & Dissertação \\
\hline $\begin{array}{l}\text { Design de Superfície: A Valorização do Museu Nacional do Mar por meio da Criação de } \\
\text { Artefatos. }\end{array}$ & Relatório Técnico \\
\hline $\begin{array}{l}\text { A Pesquisa Ação e o Design Participativo: Sensibilidade e Empatia para Abordagem em } \\
\text { Grupos Sociais. }\end{array}$ & Dissertação \\
\hline $\begin{array}{l}\text { Ecodesign de Bolsas: Um Projeto de Upcycling de Sacos de Ráfia para Comunidades } \\
\text { Artesãs da Região de Blumenau, Santa Catarina. }\end{array}$ & Relatório Técnico \\
\hline $\begin{array}{l}\text { Material têxtil e a indústria catarinense: proposta de laboratório têxtil para } \\
\text { o curso de design Univille }\end{array}$ & Relatório Técnico \\
\hline Sete trabalhos não vinculados a organizações e/ou empresas & Formato \\
\hline Acondicionamento e Coleta de Resíduos da Construção Civil em Pequenas Obras. & Relatório Técnico \\
\hline Desenvolvimento de Produtos a partir do Reuso de Materiais Metálicos Descartados. & Relatório Técnico \\
\hline As Percepções do Olhar: Uma Análise da Linguagem Fotográfica em Crianças. & Dissertação \\
\hline $\begin{array}{l}\text { Rota Segura para Dias de Inundações: Desenvolvimento de Elementos Visuais para } \\
\text { Auxiliar na Locomoção, Alerta e Localização da População. }\end{array}$ & Relatório Técnico \\
\hline $\begin{array}{l}\text { Tecnologia para Movimentação e Transferência de Pessoas com Mobilidade Reduzida } \\
\text { no Leito }\end{array}$ & Relatório Técnico \\
\hline $\begin{array}{l}\text { Diretrizes Metodológicas Projetuais para o Desenvolvimento de Produtos de Moda } \\
\text { Baseado no Design Colaborativo - Uma Proposta para as Empresas do Vale do } \\
\text { Itapocu. }\end{array}$ & Relatório Técnico \\
\hline $\begin{array}{l}\text { Princípios de Design Thinking e de Cenografia Teatral Aplicados a um Processo } \\
\text { Projetual de Design de Interiores em Ambientes de Varejo. }\end{array}$ & Relatório Técnico \\
\hline
\end{tabular}

Fonte: Mestrado Profissional em Design, 2016

Deve-se ressaltar ainda que o quadro 5 demonstra a importante contribuição para a ciência que o Mestrado Profissional em Design da Univille vem produzindo.

Dentre os desdobramentos das dissertações e dos relatórios técnicos com o setor produtivo, público e social, destaca-se que: (1) o projeto 'Aparelho para Secagem de Instrumentos Cirúrgicos' resultou em patente e, atualmente, o equipamento está sendo produzido e comercializado com o apoio de uma empresa do setor (http://www.potenzadental.com.br/potenzadry/); o empreendimento criado para tal finalidade está localizado no parque tecnológico (Inovaparq) da Univille; (2) a 
discussão realizada por meio da dissertação intitulada 'Processo Criativo em Arquitetura e Design: Afinidades e a Discussão da Identidade da Metroquadrado' evoluiu para um empreendimento denominado Atlas, que possui estrutura física e conceitual integrando ações de criatividade, arquitetura e design; (3) o projeto intitulado 'Rota Segura para Dias de Inundações: Desenvolvimento de Elementos Visuais para Auxiliar na Locomoção, Alertas e Localização da População' recebeu o Prêmio Inovação 2015 promovido pela Prefeitura de Joinville na categoria pósgraduação; (4) o equipamento de cocção resultante do projeto intitulado 'Desenvolvimento de Produtos a partir do Reuso de Materiais Metálicos Descartados' já está no processo de comercialização e foi concebido um site de apoio para a proposta disponível no blog 'Meu Reuso'; (5) os resultados obtidos por meio do projeto 'Contribuições do Design em Contexto do Terceiro Setor' foram disponibilizados para o Consulado da Mulher (instituição na qual atua e com a qual foi realizado o estudo de caso) e estão sendo usados nas capacitações das pessoas associadas a iniciativa; (6) os resultados da dissertação 'Proposta de Design de Serviços para um Sistema de Design e Artesanato: uma relação social recíproca' reorientaram ações de extensão e capacitação dos grupos de geração de renda AmaViva e SempreViva vinculados ao projeto de pesquisa SIMBOL (O design e a instituição social da cultura material e simbólica); (7) a partir das pesquisa do projeto 'Material têxtil e a indústria catarinense: proposta de laboratório têxtil para o curso de design Univille' foi constituído o Laboratório Têxtil Univille, disponível para acadêmicos e comunidade em geral, e que estará em constante atualização.

\section{CONCLUSÃO}

Responder aos desafios do setor produtivo, social e público no qual o PPGDesign/Univille está inserido e contribuir com a produção/transferência do conhecimento técnico-científico produzido na academia para a sociedade (e a ênfase na produção técnica tão relevante para os mestrados profissionais), tem sido o objetivo do programa nestes quatro anos de existência. Procura, ainda, orientar a estruturação dos grupos de pesquisa, das atividades de extensão e dos trabalhos de conclusão de curso, abrangendo também o planejamento das disciplinas: sua oferta é preliminarmente discutida com a intenção de identificar pontos de conexão e convergência, para que atividades conjuntas possam ser planejadas, bem como a continuidade de ações que se iniciem em uma disciplina e prossigam transversalmente em outra.

Uma questão fundamental considerada em todas elas é a dinamização do processo de ensino e aprendizagem, bem como o envolvimento de empresas públicas, não governamentais ou privadas - nas disciplinas, permitindo aos mestrandos contato direto com profissionais e problematizações do entorno. Essa inserção se estende com visitas técnicas, desafios projetuais integrados entre empresa-academia, seminários e mesas-redondas. As atividades práticas desenvolvidas nas disciplinas contam, portanto, com o apoio do conhecimento e da tecnologia do setor produtivo (industrial, empresarial, social).

Considera-se que o contexto local (caracterizado pela forte participação de indústrias) vem contribuindo com a inserção social do PPGDesign/Univille e para a realização de projetos em parceria. Entretanto, a ausência da cultura de parceria entre academia-empresa tem requerido um grande esforço, dentro e fora da instituição, 
para a construção das "pontes" iniciais; paralelamente, aliar o tempo do setor produtivo com o tempo acadêmico também tem exigido cuidado e atenção.

Dentre os desafios mais significativos para atender e viabilizar as metas do programa, observou-se a diferenciação que ainda existe entre mestrados acadêmicos e profissionais, no oferecimento de bolsas pelos órgãos competentes, a viabilização de patentes (em virtude dos custos e da não existência de uma política de apoio neste sentido e a incipiente cultura do trabalho conjunto entre o setor produtivo e as universidades), e a escassez de meios de divulgação da produção técnica.

Dentre as dificuldades pode ser incluído, ainda, o estranhamento da própria comunidade acadêmica, em relação ao formato dos trabalhos de conclusão de curso, fazendo com que se torne um desafio conciliar a geração de conteúdo técnico, como desenvolvimento de produtos, serviços, propriedade intelectual e depósito de patentes, com projetos de mestrado que têm duração máxima de 24 meses. Por outro lado, verifica-se um grande potencial de gerar produção técnico-científica significativa, contribuindo efetivamente com um círculo virtuoso entre academia e setor produtivo, a exemplo do que ocorre com os programas de pós-graduação de outros países que possuem forte compromisso com a conversão do conhecimento em benefícios para a sociedade.

\section{REFERÊNCIAS}

CNPQ. Diretório dos Grupos de Pesquisa no Brasil/Lattes. Disponível na internet por http em: <http://lattes.cnpq.br>. Acesso em 28 mai. 2016.

IBGE. 2014. Disponível na internet por http em: <http://www.ibge.gov.br>. Acesso em 23 mai. 2016.

JOINVILLE EM DADOS. 2015. Disponível na internet por http em:

$<$ https://ippuj.joinville.sc.gov.br/arquivo/lista/codigo/672-

Joinville\%2BCidade\%2Bem\%2BDados\%2B2015.html>. Acesso em 23 mai. 2016.

MEC. Portaria Normativa MEC no17/2009. Disponível na internet por http em:

<https://www.capes.gov.br/images/stories/download/legislacao/PortariaNormativa_1 7MP.pdf>. Acesso em 13 mai. 2016.

MESTRADO PROFISSIONAL EM DESIGN. Disponível na internet por http em:

<http://goo.gl/DbyifA>. Acesso em 23 mai. 2016.

MEU REUSO. Disponível na internet por http em:

<http://meureuso.blogspot.com.br/>. Acesso em 12 mai. 2016.

PNPG. Plano Nacional De Pós-Graduação (PNPG) 2011-2020. Brasília 2010. Disponível na internet por http em:

<https://www.capes.gov.br/images/stories/download/PNPG_Miolo_V2.pdf>. Acesso em 29 abr. 2016.

PPGDESIGN/UNIVILLE. Relatório Geral 2013 para o Coleta CAPES (Plataforma

Sucupira). Joinville : Univille. 2013.

PPGDESIGN/UNIVILLE. Relatório Geral 2014 para o Coleta CAPES (Plataforma

Sucupira). Joinville : Univille. 2014. 
PPGDESIGN/UNIVILLE. Relatório Geral 2015 para o Coleta CAPES (Plataforma Sucupira). Joinville : Univille. 2015.

UNIVILLE. APCN do Curso de Mestrado Profissional em Design. Código da Proposta: 8123. Joinville, Maio de 2012. 